\title{
CITRAAN DALAM PUISI-PUISI KARYA RATNA ROSANA, SEORANG PENYAIR WANITA KALIMANTAN SELATAN
}

\author{
(IMAGERY IN THE POEMS BY RATNA ROSANA, \\ A SOUTH KALIMANTAN WOMAN POET)
}

\author{
Agus Yulianto \\ Balai Bahasa Provinsi Kalimantan Selatan \\ Jalan A. Yani, Km 32,2 Loktabat, Banjarbaru, Kalimantan Selatan, \\ Telp.: 0511-4772641, Pos-el: agusb.indo@gmail.com
}

Diterima; 3 Agustus 2018; Direvisi: 11 Oktober 2018; Disetujui: 24 November 2018

\begin{abstract}
The objective of this research is to find out elements of imagery and meaning of Ratna Rosana's poems in her book of poem collections. The book is titled "Kabut Semu dalam Hadirmu". This research is also aimed at knowing what dominant elements of imagery used by Ratna in the poetry that she wrote. The research problems are how are imagery and meaning of the Ratna Rosana's poems in her book of poem collections described. What are the most dominant elements used by Ratna in her book of poem collections. This research uses descriptive qualitative method with recording technique and classification. Based on the results of the analysis, this research shows that the poems written by Ratna Rosana apply a lot of imagery to stress the meaning of image such as image of visions, hearings, touches, smells, movements, and senses.
\end{abstract}

Keywords: poetry, imagery, Ratna

\begin{abstract}
Abstrak
Tujuan penelitian ini adalah untuk mengetahui unsur-unsur citraan yang terdapat dalam puisi-puisi Ratna Rosana yang terdapat dalam buku kumpulan puisinya yang berjudul Kabut Semu dalam Hadirmu serta makna yang terdapat di dalamnya. Selain itu, juga untuk mengetahui unsur citraan apa yang paling dominan dipakai oleh Ratna di dalam karya-karya puisi yang dihasilkannya. Adapun masalah dalam penelitian ini adalah bagaimana pencitraan yang terdapat dalam puisi-puisi Ratna Rosana yang terdapat dalam buku kumpulan puisinya tersebut beserta maknanya serta unsur pencitraan apa yang paling dominan dipakai oleh Ratna di dalam buku kumpulan puisinya tersebut. Penelitian ini menggunakan metode deskriptif kualitatif dengan teknik catat dan klasifikasi.Berdasarkan hasil analisis dapat diketahui bahwa puisi-puisi karya
\end{abstract}


Ratna Rosana banyak menggunakan citraan untuk mempertegas makna imaji seperti citraan indera penglihatan, pendengaran, perabaan, pencecapan, penciuman, gerak, dan perasaan.

Kata kunci: puisi, citraan, Ratna 


\section{Pendahuluan}

Menurut Pradopo (2014: 7) puisi itu merupakan pengekspresian pemikiran yang membangkitkan perasaan yang merangsang imajinasi pancaindera dalam susunan yang berirama. Semua itu merupakan sesuatu yang penting yang direkam dan diekspresikan, dinyatakan dengan menarik dan memberi kesan. Puisi itu merupakan rekaman dan interpretasi pengalaman manusia yang penting digubah dalam wujud yang paling berkesan.

Rangsangan imaji yang terdapat dalam puisi salah satunya disebabkan terdapatnya aspek citraan dalam puisi itu sendiri. Penggunaan citraan dalam puisi itu sendiri berfungsi untuk 1) memberikan gambaran yang jelas; 2) menimbulkan suasana yang khusus; 3) membuat hidup gambaran dalam pikiran dan penginderaan; dan 4) menarik perhatian pembaca. Dengan demikian, citraan dalam sebuah puisi berguna pula untuk lebih memahami makna sebuah puisi secara lebih mendalam. Oleh sebab itu, para penyair selalu menggunakan citraan ini dalam membuat karya puisinya.

Penyair yang ada di Kalimantan selatan cukup banyak dan juga sangat produktif dalam menghasilkan karya sastra. Akan tetapi, penyair yang berjenis kelamin wanita masih belum terlalu banyak. Oleh sebab itu, pengapresiasian karya puisi seorang penyair wanita Kalimantan Selatan menjadi menarik untuk dilakukan. Salah satu penyair wanita yang ada di Kalimantan Selatan adalah Ratna Rosana. Ratna Rosana lahir di Kota Pelaihari, Tanah Laut, Kalimantan Selatan pada tanggal 18 Desember 1963. Dia menyelesaikan pendidikan sarjananya di Universitas Achmad Yani Banjarmasin pada tahun 1994. Selanjutnya, dia menyelesaikan pendidikan pascasarjana di jurusan Bahasa dan Sastra Indonesia Universitas Lambung Mangkurat dan lulus tahun 2008. Ia juga telah menyelesaikan pendidikan S-3 di Universitas Negeri Malang. Saat ini, Ratna mengajar di beberapa universitas yang ada di Kalimantan Selatan.

Salah satu karya Ratna di bidang perpuisian adalah dengan terbitnya kumpulan puisi karyanya yang diberi judul Kabut Semu dalam Hadirmu pada tahun 2015. Buku kumpulan puisi ini memuat 79 buah puisi hasil karyanya. Puisi-puisi yang dihasilkan oleh Ratna ini juga memuat unsur citraan. Oleh sebab itu, menjadi menarik untuk menganalisis unsur citraan yang dipakai oleh salah satu pengarang wanita Kalimantan Selatan terebut. Citraan apa yang dominan dipakai oleh Ratna akan terkuak secara sendirinya dalam analisis yang akan 
dilakakukan kemudian. Dengan demikian, tujuan penelitian ini adalah untuk mengetahui unsur-unsur citraan yang terdapat dalam puisi-puisi Ratna Rosana yang terdapat dalam buku kumpulan puisinya yang berjudul Kabut Semu dalam Hadirmu dan makna yang terdapat di dalamnya. Selain itu, tujuan penelitian ini untuk mengetahui unsur citraan apa yang paling dominan dipakai oleh Ratna di dalam karya-karya puisi yang dihasilkannya. Adapun masalah yang diangkat dalam penelitian ini adalah bagaimana pencitraan yang terdapat dalam buku kumpulan puisi karya Ratna Rosana beserta maknanya serta unsur pencitraan apa yang paling dominan dipakai oleh Ratna di dalam buku kumpulan puisinya tersebut.

\section{Kerangka Teori}

Emerson (dalam Syahruddin, 2009:2) memberikan penjelasan bahwa puisi merupakan upaya abadi untuk mengekspresikan jiwa sesuatu, untuk menggerakkan tubuh yang kasar dan mencari kehidupan dan alasan yang menyebabkan ada. Pradopo (2014:3) menyatakan bahwa puisi merupakan sebuah hasil karya sastra seni yang tersusun dari bermacam-macam unsur dan sarana-sarana kepuisian. Puisi itu karya estetis yang bermakna, yang mempunyai arti, bukan hanya sesuatu yang kosong tanpa makna. Selanjutnya, Waluyo (dalam Dzar Al Banna, 2010: 1) menyatakan bahwa puisi adalah karya sastra dengan bahasa yang dipadatkan, dipersingkat dan diberi irama dengan bunyi yang padu dan pemilihan kata-kata kias.

Lebih jauh, Suroto (2005: 20-21) menyatakan bahwa pencitraan atau imaji adalah pengungkapan perasaan sensoris penyair kedalam kata dan ungkapan sehingga terjelma gambaran suasana yang lebih konkret. Menurut Waluyo (1995:78) pencitraan dibatasi oleh pengertian kata atau susunan kata yang dapat mengungkapkan pengalaman sensoris seperti penglihatan, pendengaran dan perasaan.

Menurut Zaidan (2006:65), citraan adalah daya bayang yang dihasilkan dari pengolahan kata-kata secara sungguhsungguh untuk memberikan kesan indah di dalam suatu puisi; suatu penggambaran pengalaman yang berkaitan dengan benda, peristiwa, dan keadaan yang dialami penyair dengan memakai kata-kata yang bersifat khas agar dapat memberikan gambaran secara lebih nyata, baik hal-hal yang bersifat kebendaan, metaforik, ataupun kejiwaan.

Menurut Pradopo (2014: 79), dalam puisi, untuk memberi gambaran yang jelas, untuk menimbulkan suasana yang khusus, untuk membuat (lebih) hidup gambaran 
dalam pikiran dan penginderaan dan juga untuk menarik perhatian, penyair menggunakan gambaran-gambaran angan (pikiran), di samping alat kepuitisan yang lain. Gambaran-gambaran angan dalam sajak itu disebut citraan (imagery).

Selanjutnya Altenbernd (dalam Pradopo, 2014: 79—80) menyatakan citraan ini adalah gambar-gambar dalam pikiran dan bahasa yang menggambarkannya, sedangkan setiap gambar pikiran disebut citra atau imaji (image). Gambaran pikiran ini adalah sebuah efek dalam pikiran yang sangat menyerupai (gambaran) yang dihasilkan oleh penangkapan kita terhadap sebuah objek yang dapat dilihat oleh mata, saraf penglihatandan daerah-daerah otak yang sangat berhubungan (bersangkutan). Berhubungan dengan hal itu, arti kata harus diketahui dan dalam hubungan ini mungkin juga berarti bahwa orang harus dapat mengingat sebuah pengalaman indraan atas objek-objek yang disebutkan atau diterangkan.

Nugroho (2009) menyatakan bahwa citraan puisi adalah penggambaran mengenai objek berupa kata, frase, atau kalimat yang tertuang di dalam puisi atau prosa. Citraan dimaksudkan agar pembaca dapat memperoleh gambaran konkret tentang hal- hal yang ingin disampaikan oleh pengarang atau penyair.

Menurut Coombes (dalam Pradopo, 2014: 80), dalam tangan seorang penyair yang bagus, imaji itu segar dan hidup, berada dalam puncak keindahannya untuk mengintensifkan, menjernihkan, memperkaya sebuah imaji yang berhasil menolong orang merasakan pengalaman penulis terhadap objek dan situasi yang dialaminya, dan memberi gambaran yang setepatnya, hidup, kuat, ekonomis, dan segera dapat kita rasakan dan dekat dengan hidup kita sendiri. Lebih jauh Coombes (dalam Pradopo, 2014: 42-43) mengemukakan bahwa pembuatan gambaran hendaknya jangan berada di luar pengalaman kita, misalnya, sebuah imaji. Imaji konvensional atau klise tidak dapat memberi efek puitis dan tidak menghidupkan gambaran, misalnya "seputih kertas", bahkan lebih efektif jika dikatakan " ia sangat pucat."

Lebih jauh Pradopo (2014: 81) memaparkan gambaran-gambaran angan itu ada bermacam-macam, dihasilkan oleh indera penglihatan, pendengaran, perabaan, pencecapan, dan penciuman, bahkan juga diciptakan oleh pemikiran dan gerakan.

Di bawah ini, terdapat jenis-jenis citraan atau imaji. 


\section{a. Citra Penglihatan (Visual Imagery)}

Citra penglihatan adalah jenis yang paling sering dipergunakan oleh penyair dibandingkan dengan citraan yang lain. Citra penglihatan memberi rangsangan kepada inderaan penglihatan, hingga sering hal-hal yang tak terlihat jadi seolah-olah terlihat.

\section{b. Citra Pendengaran (Auditory Imagery)}

Citra pendengeran yaitu citraan itu dihasilkan dengan menyebutkan atau menguraikan bunyi suara (Altenbernd dalam Pradopo, 2014:82). Citraan pendengaran adalah citraan yang dihasilkan dengan menyebutkan atau menguraikan bunyi suara. Citraan pendengaran berhubungan dengan kesan dan gambaran yang diperoleh melalui indera pendengaran (telinga), contohnya camar bernyanyi, suara gemuruh dalam kelam.

\section{c. Citra Perabaan (Tactile Imagery)}

Citraan perabaan adalah citraan yang dapat dirasakan oleh indera peraba (kulit). Pada saat membacakan atau mendengarkan larik-larik puisi, kita dapat menemukan diksi yang dapat dirasakan kulit, misalnya dingin, panas, lembut, kasar, dan sebagainya.

\section{d. Citra Pencecapan (Gustatory)}

Citraan pencecapan adalah citraan yang berhubungan dengan kesan atau gambaran yang dihasilkan oleh indera pengecap. Pembaca seolah-olah mencicipi sesuatu yang menimbulkan rasa tertentu seperti pahit, manis, asin, pedas, enak, nikmat, dan lainlain.

\section{e. Citra Penciuman (Olfactory)}

Citraan penciuman adalah citraan yang berhubungan dengan kesan atau gambaran yang dihasilkan oleh indera penciuman. Citraan ini tampak saat kita membaca atau mendengar kata-kata tertentu, kita seperti mencium sesuatu.

\section{f. Citra Gerak}

Citraan gerak yaitu citraan yang secara konkret tidak bergerak, tetapi secara abstrak objek tersebut bergerak.

\section{g. Citra Perasaan}

Citraan perasaan yaitu citraan yang melibatkan hati (perasaan). Citraan ini membantu kita dalam menghayati suatu objek atau kejadian yang melibatkan perasaan.

Dengan demikian, jenis-jenis citraan inilah yang digunakan sebagai landasan analisis dalam pembahasan citraan dalam puisi-puisi karya Ratna Rosana.

\section{Metode Penelitian}

Penelitian ini menggunakan metode deskriptif kualitatif dengan teknik studi pustaka. Data yang diperoleh disajikan dalam bentuk deskriptif sebagai ciri khas penelitian kualitatif. Semi (2012:23) menyatakan 
bahwa metode deskriptif adalah metode yang dilakukan dengan tidak menggunakan angkaangka, tetapi menggunakan penghayatan terhadap interaksi antarkonsep yang sedang dikaji secara empiris. Menurut Moleong (2007:6), penelitian kualitatif adalah penelitian yang bermaksud memahami fenomena tentang apa yang dialami subjek penelitian secara holistik dan dengan cara deskripsi dalam bentuk kata-kata dan bahasa, pada konteks khusus yang alamiah dan dengan memanfaatkan berbagai metode ilmiah. Analisis ini berusaha untuk mendeskripsikan unsur citraan yang terdapat dalam buku kumpulan puisi Ratna Rosana yang berjudul Kabut Semu dalam Hadirmu.

Teknik penelitian yang dilakukan dengan menggunakan teknik studi pustaka, yaitu dengan mengambil buku-buku yang relevan dengan penelitian. Selain itu, teknik analisis data yang dilakukan yaitu dengan mengambil penggalan puisi yang mengandung unsur citraan kemudian dianalisis kategori citraan dan maksud penggunaannya.

\section{Pembahasan}

Jumlah puisi yang terdapat dalam buku kumpulan puisi Kabut Sети dalam Hadirmu adalah 79 buah puisi. Akan tetapi, tidak semua puisi dijadikan sebagai objek penelitian. Puisi yang dijadikan objek penelitian hanya berjumlah dua belas puisi saja yang dianggap cukup mewakili karena banyak mengandung unsur citraan di dalamnya. Puisi-puisi tersebut adalah: Panorama, Kau Bintangku, Makhluk Apakah Kau?, Ibu, Dalam Renunganku, Lonceng Kehidupan, Perkawinan, Kabut Semu dalam Hadirmu, Cinta Tak Berbalas, Bercumbu, Masa Lalumu, dan Darurat Narkoba.

Perhatikan citraan dalam puisi-puisi Ratna Rosana pada uraian berikut.

\subsection{Citraan Penglihatan(Visual Imagery)}

Citraan penglihatan merupakan citraan yang paling banyak dipakai oleh Ratna dalam puisi-puisinya. Dalam puisi yang berjudul Panorama, citraan penglihatan terlihat dalam kutipan berikut.

Datanglah kepadaku seuntai harap Harap tentang warna pelangi Hijau kuning merah abu abu Kau kah itu?

Kutipan puisi di atas menjelaskan bahwa harapan yang diinginkan adalah harapan yang indah seindah pelangi. Harapan yang penuh warna-warni. Dengan demikian, harapan yang dinanti adalah harapan tentang sebuah kebaikan yang dapat berupa perbuatan ataupun pemikiran.

Citraan penglihatan juga terlihat dalam puisi yang berjudul Kau Bintangku.

Dalam genggaman kabut malam 
Kupandang langit ingatkan kelam

Kau.... bintangku bercahaya semu

Semu dalam deru nafasmu.

Kutipan di atas menggambarkan bahwa sang tokoh dalam puisi sedang memandang langit dan mengingatkannya pada sebuah kenangan yang kelam. Kenangan yang buruk yang menimbulkan rasa tidak nyaman dalam diri. Selanjutnya, sosok yang sedang dikenang itu layaknya sebagai sebuah bintang atau orang yang baik. Akan tetapi, ternyata kebaikan itu hanya bersifat semu belaka.

Pagi...redup tak bersinar

Menjelang siang asa terlihat

Tiba petang menjelang malam

Bintang menyusul sang rembulan

Kutipan ini menggunakan citraan penglihatan untuk menggambarkan awal sebuah kehidupan yang temaram dan suram. Akan tetapi, kesuraman itu tidak berlangsung lama. Hal itu disebabkan pada pertengahan hari atau pada pertengahan kehidupan harapan mulai terlihat.

Lembut kelam seperti bayu Semilir angin tangkap citaku Ke arah merah gemuruh hati Mendulang cinta dalam harapanmu

Citraan penglihatan yang terdapat dalam kutipan di atas menggambarkan rasa semangat yang membara sehingga seakanakan terlihat merah atau memerah. Semangat itu menggemuruhkan hati untuk dapat meraih asa berupa sebuah cinta.

Puisi yang berjudul Makhluk Apakah

Kau? juga mengandung unsur citraan penglihatan.

Bibir manis berpoles merah

Nuansa parfummu menusuk aroma

Tapi...kau gulirkan sepi

Kau ciptakan nestapaku

Citraan penglihatan yang terdapat dalam kutipan di atas menggambarkan sebuah bibir yang dipoles merah sehingga menimbulkan penglihatan yang sangat menawan. Akan tetapi, keindahan dan kemenawanan itu ternyata malah menimbulkan nestapa. Hal itu disebabkan rasa sepi yang dihadirkannya.

Puisi yang berjudul $I b u$ ini juga mengandung citraan penglihatan.

Ibu, engkau cahaya dalam hidupku

Engkau penerang jalanku

Engkau penunjuk arah hidupku

Citraan penglihatan di atas menggambarkan tentang pengagungan yang tinggi dari seorang anak terhadap ibunya. Ibu adalah orang yang sangat berjasa bagi kehidupan seorang anak. Ibulah yang melahirkan, mendidik, membesarkan seorang anak sehingga menjadi orang yang berguna. Oleh sebab itu, tidak heran bila jasa seorang ibu sungguh tidak ternilai di hadapan anak-anaknya. 


\subsection{Citraan Pendengaran (Auditory Imagery)}

Citraan pendengaran terdapat dalam puisi Ratna yang berjudul Dalam Renunganku.

Terlena dalam desah malam

Kurcaci bernyanyi menuai kelam

Sepi...terhanyut...larut

Seraut mimpi membekas pilu

Citraan pendengaran ini menggambarkan tentang malam yang seakan-akan mendesah sehingga melenakan. Selain itu, penggambaran makhluk dongeng berupa kurcaci yang bernyanyi terasa kontras dengan tuaian hasilnya yang berupa kekelaman atau sebuah kesuraman.

Citraan pendengaran juga terlihat dalam puisi Lonceng Kehidupan.

Dalam pelukan malam kuterhempas Genggaman muram lagu syahdu Gemerincing lonceng nyanyian sepi Akankah berlalu.....?

Citraan pendengaran ini menggambarkan tentang gemerincing suara lonceng yang justru menimbulkan sebuah irama atau nyanyian yang sunyi. Hal itu dapat disebabkan oleh lokasi atau hati yang merasa sepi walaupun di tengah gemerincing suara lonceng.

Citraan pendengaran berikut terlihat dalam puisi yang berjudul Perkawinan.
Suara gamelan memecah sunyi

Suara alam bersahutan ceria

Dalam rengkuh kemeja remaja

Dengus langkah berlari kencang

Citraan pendengaran ini menggambarakan suara gamelan yang memecah kesunyian. Selain itu, suara alam yang dapat berupa suara burung dan serangga menimbulkan efek keceriaan dan kecerahan suasana. Hal itu menimbulkan asosiasi suasana yang hangat dan ceria.

Citraan pendengaran juga terdapat dalam puisi yang berjudul Kabut Semu Dalam Hadirmu.

Tabir surya merasuk bumi

Tenggelam tersedu pilu

Panorama itu adalah nyanyian sumbang

Sumringah bersatu kegelapan

Dalam puisi ini, citraan pendengaran yang digunakan menggambarkan sebuah pemandangan atau panorama yang justru menimbulkan sebuah irama yang sumbang. Hal itu disebabkan rasa pilu dan kesedihan yang sedang mendera.

Puisi yang berjudul $I b u$ juga terdapat citraan pendengaran. Cintraan tersebut sebagai berikut.

Ibu, engkau selalu mengajariku

Tentang harumnya bunga dan pahitnya empedu

Tentang nyanyian malam yang syahdu

Dan tentang nyanyian bulan yang terang benderang 
Citraan pendengaran dalam kutipan ini menggambarkan tentang nyanyian malam yang disebabkan oleh bunyi suara serangga yang menimbulkan suasana yang syahdu. Selain itu, pengandaian bulan yang bernyanyi menimbulkan asosiasi keadaan yang ceria dan terasa segar.

Ibu, tanganmu yang lusuh tercabik rindu

Bagai kidung nurani senja hari

Kau selalu dan selalu

Memberikan apa arti hitam dan putih

Citraan pendengaran dalam kutipan

di atas menggambarkan tentang perjuangan seorang ibu yang memperjuangkan anaknya. Tangannya yang selama ini membesarkan anaknya terlihat tampak lusuh. Akan tetapi, tangan yang telah lusuh itu menerbitkan rasa rindu. Rindu yang menentramkan seperti nyanyian kidung yang menentramkan nurani.

Namun kadang kau tersedak rindu

Kadang kau merintih bias

Kadang alam tak bersahabat denganmu

Kadang kau memang pergi ke alam lain

Citraan pendengaraan dalam kutipan di atas menggambarkan kesusahan dan kepedihan dalam membesarkan seorang anak. Seorang ibu dalam membesarkan anaknya tentulah tidak selamanya selalu berjalan mulus. Terkadang terdapat hambatan dan cobaan dalam membesarkan anaknya itu. Tidak heran, bila terkadang seorang ibu merintih sebagai wujud dari kesusahannya dalam mendidik anak. Akan tetapi, semua itu bukan berarti sang ibu mengeluh. Sang ibu hanya sekadar melepaskan sedikit beban dalam pelaksanaan tanggung jawab besarnya dalam mendidik seorang anak.

Puisi Ratna yang berjudul Cinta Tak Terbalasjuga mengandung unsur citraan pendengaran.

Hujan deras cerita tentangmu Menjadi koleksi ditelingamu Bagai alunan melodi merdu

Yang tak dapat pudar dimakan waktu

Citraan pendengaran dalam kutipan di atas menggambarkan tentang rasa suka dan cinta terhadap seseorang. Rasa cinta itu membuat segala sesuatu yang berhubungan dengan orang yang dicntai menjadi terasa indah. Bahkan, cerita tentang orang itu saja sudah indah. Keindahan itu diibaratkan dengan alunan melodi yang merdu.

\subsection{Citraan Perabaan (Tactile Imagery)}

Citraan dalam puisi-puisi Ratna antara lain terdapat dalam puisinya yang berjudul Kau Bintangku.

Lembut kelam seperti bayu Semilir angin tangkap citaku Ke arah merah gemuruh hati Mendulang cinta dalam harapanmu 
Citraan perabaan yang terdapat dalam kutipan di atas menggambarkan tentang lembutnya keremangan atau kegelapan disebabkan rasa suka terhadap seseorang. Rasa suka itu menimbulkan efek keceriaan walaupun pada sesuatu yang bersifat kelam. Bahkan, kelam itu diibaratkan seperti kelembutan angin.

Citraan perabaan juga terdapat dalam puisi Ratna yang berjudul Bercumbu.

Alam indah nan berseri

Kerinduan akan cumbuanmu

Cumbu mesra di malam dingin

Mabuk cinta asmara salju

Citra perabaan yang terdapat dalam kutipan dia atas menggambarkan tentang sepasang insan yang sedang merindu dendam. Rindu cumbu mesra di malam yang terasa dingin. Malam dingin yang tidak memengaruhi sepasang insan yang sedang dimabuk cinta.

Puisi Ratna yang berjudul Masa Lalumu juga terdapat citraan peraba. Berikut penggalan puisinya.

Di atas hijaunya rerumputan

Rumput yang masih dingin dengan butiran embun

Kaki berpijak berlari-larian

Lewati pagi bersama kawan

Citra perabaan yang terdapat dalam kutipan di atas menggambarkan tentang dinginnya rerumputan di pagi hari. Rerumputan yang menjadi saksi kebersamaan antara dua orang sahabat. Mereka berlari-larian di atas rumput yang dingin melewati kebersamaan yang indah.

Hangat mentari yang menghampiri Menyingkap sebuah dinginnya hari Menembus sinaran sang surya pagi Agar bisa hangat diri

Citra perabaan yang terdapat dalam kutipan di atas menggambarkan tentang sinar matahari di pagi yang menimbulkan kehangatan di alam. Kehangatan sinar mentari itu perlahan-lahan menghilangkan dinginnya hari akibat dinginnya malam. Selain itu, sinar mentari tersebut juga perlahan-lahan menimbulkan kehangatan bagi tubuh.

\subsection{Citraan Pencecapan (Gustatory)}

Puisi Ratna yang berjudul $I b u$ juga memiliki citraan pencecapan. Berikut penggalan puisinya.

Ibu, engkau selalu mengajariku

Tentang harumnya bunga dan pahitnya empedu

Tentang nyanyian malam yang syahdu

Dan tentang nyanyianbulan yang terang benderang

Citraan pencecapan yang terdapat dalam kutipan di atas menggambarkan tentang pembelajaran kehidupan yang diberikan oleh seorang ibu kepada anaknya. Hidup ini terkadang menyenangkan dan juga terkadang menyakitkan. Suka dan duka 
akanselalu berganti hadir dalam kehidupan manusia. Kepahitan hidup itu diibaratkan seperti menelan empedu. Sang ibu mengajari anaknya tentang kemanisan hidup juga tentang kepahitan hidup. Kemanisan hidup seharusnya menjadikan manusia bersyukur dan kepahitan hidup mengharuskan manusia bersabar.

\subsection{Citraan Penciuman}

Puisi karya Ratna yang berjudul Makhluk Apakah Kau? ini mengandung unsur citraan penciuman.

Bibir manis berpoles merah

Nuansa parfummu menusuk aroma

Tapi...kau gulirkan sepi

Kau ciptakan nestapaku

Citraan penciuman dalam kutipan puisi di atas menggambarkan tentang keharuman parfum tubuh seorang wanita. Parfum tersebut seharusnya memberikan kegairahan dan keceriaan. Akan tetapi, harumnya parfum tersebut ternyata menimbulkan efek sebaliknya, yaitu menciptakan rasa sepi. Rasa sepi tersebut tercipta bersama-sama dengan terciptanya rasa nestapa.

Puisi Ratna yang berjudul $I b u$ juga memiliki citraan penciuman. Berikut penggalan puisinya.

Ibu, engkau selalu mengajariku

Tentang harumnya bunga dan pahitnya empedu
Tentang nyanyian malam yang syahdu

Dan tentang nyanyian bulan yang terang benderang

Citraan penciuman dalam kutipan puisi di atas menggambarkan tentang pelajaran hidup yang diberikan seorang ibu kepada anaknya. Sang ibu mengajarkan tentang kebahagiaan, kesenangan hidup yang diibaratkan sebagai harumnya bunga. Walaupun dalam kata-kata berikut sang ibu juga mengajarkan tentang kepahitan hidup agar sang anak memahami tentang dinamika kehidupan ini.

\subsection{Citraan Gerak}

Citraan gerak juga dipakai oleh Ratna dalam puisi-puisi yang diciptakannya. Citraan tersebut antara lain terdapat dalam puisi yang berjudul Kau Bintangku.

Lembut kelam seperti bayu Semilir angin tangkap citaku

Ke arah merah gemuruh hati

Mendulang cinta dalam harapan

Citraan gerak dalam kutipan puisi di atas menggambarkan tentang perasaan cinta seseorang yang menyebar dan menyeruak sehingga semilir angin pun dapat merasakan dan menangkap cinta tersebut. Dengan kata lain, rasa cinta itu menyatu dalam semilir angin yang berhembus.

Meski hanya gugusan bintang Tapi kuberlari memegang

Sebelum bintang memudar siang 
Asa tertangkap meskipun semu

Selanjutnya, citraan gerak dalam sambungan kutipan puisi di atas menggambarkan tentang simbolisasi memegang gugusan bintang yang dapat diartikan sebagai memegang sebuah harapan walaupun bersifat semu. Gugusan bintang yang keesokan harinya memudar memberikan sebuah pemahaman tentang menghargai sebuah asa meskipun asa tersebut masih bersifat semu.

Selanjutnya puisi Ratna yang berjudul $I b u$ juga memuat citraan gerak.

Aku....mengapa terlahir tanpa pelangi itu

Ibu...kaulah itu

Meraung menerkam merajut malam Gelap disaput rona....

Citraan gerak dalam kutipan puisi di atas menggambarkan tentang keperkasaan seorang ibu yang menjaga anak-anaknya. Ibu diibaratkan binatang buas yang dapat menerkam ketika hal itu dikaitkan demi untuk menjaga keamanan dan keselamatan anak-anaknya. Ibu terkadang dianggap sebagai wanita lemah. Padahal ibu adalah sosok yang rela melakukan apa saja demi untuk menjaga anak-anaknya.

Puisi Ratna yang berjudul Panorama juga mengandung citraan gerak.

Ingin kupeluk rindu dihadapanmu Hamparan mentari kelamkan jiwa
Seonggok nafas balutan renda Renda renda tidak bertepi

Citraan gerak dalam kutipan puisi di atas menggambarkan tentang pengiasan rasa rindu terhadap sesuatu atau seseorang. Rindu tersebut sangat disukai. Oleh sebab itu, seakan-akan ingin sekali memeluk rasa rindu itu.

\subsection{Citraan Perasaan}

Citraan perasaan yang terdapat dalam puisi Ratna antara lain terdapat dalam puisinya yang berjudul Makhluk Apakah Kau?

Seisi alam meronta, menerjang meregang

Porak poranda tersaput bisu

Kelam perih dan pedih

Aku bertanya siapa kau?

Citraan perasaan dalam kutipan di atas menggambarkan tentang sebuah prahara yang terjadi. Prahara itu menciptakan rasa kelam dan pedih. Kekelaman dan kepedihan itu diakibatkan oleh sesosok makhluk yang seakan-akan tidak dapat dikenali siapa dirinya. Hal itu disebabkan kerusakan yang ditimbulkannya begitu terasa memedihkan. Oleh sebab itu, pertanyaan siapakah jati diri makhluk itu sebenarnya merupakan pertanyaan retorik untuk menyindir betapa besar daya rusak yang dimiliki makhluk itu. 
Demikian juga dalam puisi Ratna yang berjudul Cinta Tak Terbalas, citraan perasaan terdapat di sana.

Ingin kumilikimu

Ingin kumendengarmu

Dan ingin kumerasakan cintamu

Citraan perasaan dalam kutipan di atas menggambarkan tentang sebuah harapan yang sangat tinggi untuk memiliki sebuah cinta dari orang yang sangat dikagumi. Cinta yang dinanti tumbuh berdasarkan keinginan yang sangat kuat untuk mendapatkan cinta dari orang yang dicintai. Akan tetapi, cinta itu tidak pernah di dapat disebabkan cintanya bertepuk sebelah tangan.

Citraan perasaan yang lain juga terdapat dalam puisi Ratna yang berjudul Darurat Narkoba. Berikut penggalan puisinya.

Aku takut, sedih, kecewa, menangis tanpa air mata

Jika suatu saat kelak bumi Pertiwi kita terberai remuk

Oleh radiasi penyongsong bangsa yang hampa Ingat, sadarlah.....

Citraan perasaan dalam kutipan di atas menggambarkan tentang rasa kekhawatiran yang sangat luar biasa terhadap keselamatan Bumi Pertiwi. Bumi Pertiwi atau Indonesia ini memang terkadang dilanda masalah yang terus menerus, baik itu berupa korupsi, narkoba, sara, dan lain-lain yang kesemuanya dapat menyebabkan Bumi Pertiwi ini menjadi porak poranda.

\subsection{Citraan yang Paling Dominan}

Setelah menganalisis beberapa puisi karya Ratna yang dijadikan sampel penelitian, citraan yang paling dominan dipakai oleh Ratna dalam membuat puisipuisinya adalah citraan pendengaran. Jumlah puisi yang memakai citraan pendengaran oleh Ratna ini berjumlah enam buah puisi. Puisi-puisi tersebut adalah Dalam Renunganku, Lonceng Kehidupan, Perkawinan, Kabut Semu dalam Hadirmu, Ibu, dan Cinta Tak Berbalas.

Jumlah puisi Ratna yang memakai citraan penglihatan berjumlah empat buah puisi, yaitu: Panorama, Kau Bintangku, Makhluk Apakah Kau? dan Ibu. Jumlah puisi Ratna yang memakai citraan perabaan berjumlah tiga buah puisi, yaitu Kau Bintangku, Bercumbu, dan Masa Lalumu. Jumlah puisi Ratna yang memakai citraan pencecapan berjumlah satu buah puisi, yaitu Ibu. Jumlah puisi Ratna yang memakai citraan penciuman berjumlah dua buah puisi, yaitu: Makhluk Apakah Kau? dan Ibu. Jumlah puisi Ratna yang memakai citraan gerak berjumlah tiga buah puisi, yaitu Kau Bintangku. Ibu, dan Panorama. Jumlah puisi Ratna yang memakai citraan perasaan berjumlah tiga buah puisi, yaituMakhluk 
Apakah Kau?, Cinta Tak Terbalas, dan Darurat Narkoba.

\section{Penutup}

Ratna sebagai penyair wanita dari Kalimantan Selatan dalam membuat puisi menggunakan citraan-citraan yang dapat membangun gambaran angan dalam puisinya. Citraan-citran yang terdapat dalam puisi-puisi Ratna meliputi citraan penglihatan, pendengaran, perabaan, pencecapan, penciuman, gerak, dan perasaan.

Citraan penglihatan terlihat antara lain dalam puisinya yang berjudul Panorama, Kau Bintangku, Makhluk Apakah $K a u$ ? dan $I b u$. Citraan pendengaran antara lain terdapat dalam puisi yang berjudul Dalam Renunganku, Lonceng Kehidupan, Perkawinan, Kabut Semu dalam Hadirmu, Ibu, dan Cita Tak Terbalas. Citraan perabaan antara lain terdapat dalam puisi yang berjudul Kau Bintangku, Bercumbu, dan Masa Lalumu. Citraan pencecapan terdapat dalam puisi yang berjudul $I b u$. Citraan penciuman terdapat dalam puisi Ratna yang berjudul Makhluk Apakah Kau? dan Ibu. Citraan gerak terdapat dalam puisi Ratna antara lain dalam puisi yang berjudul Kau Bintangku, $I b u$, dan Panorama. Citraan perasaan terdapat antara lain dalam puisi Ratna yang berjudul Makhluk Apakah Kau? Cinta Tak Terbalas, dan Darurat Narkoba.

Ratna menggunakan unsur citraan dalam puisinya untuk dapat lebih menciptakan gambaran angan bagi para pembaca. Gambaran angan itu digunakan untuk membuat puisi menjadi jelas, untuk menimbulkan suasana, dan untukmembuat menjadi lebih hidup dan menarik. Sementara itu, citraan yang paling dominan dipakai oleh Ratna dalam puisi-puisinya adalah citraan pendengaran.

\section{Daftar Pustaka}

Al Banna, Dzar. (2010). Analisis Puisi "dengan puisi, Aku" Karya Taufiq Ismail. Dalam http://dzaralbannasastra.blogspot.co $\mathrm{m} / 2010$ / dikutip on line pada tanggal 9 januari 2018.

Moleong, Lexy. J. (2007). Metode Penelitian Kualitatif. Bandung: Remaja Rosda Karya.

Nugroho, Ernest. (2009). Goedang Bahasa dan Sastra. Dalam gubukbahasasastra.blogspot.com, dikutip online pada tanggal 9 Januari 2018.

Pradopo, Rahmat Djoko. (2014). Pengkajian Puisi. Yogyakarta: Gajah Mada University Press. 
Rosana, Ratna. (2015). Kabut Semu dalam Hadirmu. Banjarmasin: Grafika Wangi.

Semi, Atar. (2012). Metode Penelitian Sastra. Bandung: Angkasa Jaya.

Suroto, Djojo. (2005). Puisi: Pendekatan dan Pembelajaran. Bandung: Nuansa Cendikia.

Syahruuddin. (2009). Apresiasi Puisi. Makassar: CV. Permata Ilmu.

Waluyo, Herman J. (1995). Teori dan Apresiasi Puisi. Jakarta: Erlangga.

Zaidan, Abdul Razak. (2006). Kamus Istilah Sastra. Jakarta: Pusat Pembinaan dan Pengembangan Bahasa. 